\title{
The value of small-airway function variables in spirometry, fractional exhaled nitric oxide, and circulating eosinophils for predicting bronchial hyperresponsiveness in patients with mild asthma
}

\author{
Wuping Bao ${ }^{1}$, Xue Zhang ${ }^{1}$, Junfeng Yin ${ }^{2}$, Zhixuan Huang ${ }^{2}$, Lei Han ${ }^{1}$, Luhong Bao ${ }^{1}$, \\ Chengjian $\mathrm{Lv}^{1}$, Huijuan $\mathrm{Hao}^{1}$, Yishu Xue ${ }^{1}$, xin Zhou ${ }^{1}$, and Min Zhang ${ }^{3}$ \\ ${ }^{1}$ Shanghai Jiaotong University First People's Hospital \\ ${ }^{2}$ Tongji University \\ ${ }^{3}$ Shanghai Jiao Tong University
}

September 28, 2020

\begin{abstract}
Background: Patients with variable symptoms suggestive of asthma but with normal forced expiratory volume in 1 second (FEV1) often fail to be diagnosed without a bronchial provocation test, but the test is expensive, time-consuming, risky and not readily available in all clinical settings. Methods: A cross-sectional study was performed in 692 patients with FEV1[?]80\% predicted; normal neutrophils and chest high-resolution computed tomography; and recurrent dyspnea, cough, wheeze, and chest tightness. Results: Compared with subjects negative for BHR $(\mathrm{n}=522)$, subjects positive for BHR $(\mathrm{n}=170)$ showed increased FENO values, EOS, and R5-R20; decreased FEV1, FEV1/Forced vital capacity (FVC), and forced expiratory flow (FEFs) (P[?].001 for all). Small-airway dysfunction was identified in 104 BHR + patients (61.17\%), and 132 BHR- patients (25.29\%) $(\mathrm{P}<.001)$. The areas under the curve $(\mathrm{AUCs})$ of variables used singly for a BHR diagnosis were lower than 0.77 . Using joint models of FEF50\%, FEF75\%, or FEF25\%-75\% with FENO increased the AUCs to 0.845, 0.824, and 0.844, respectively, significantly higher than univariate AUCs $(\mathrm{P}<.001$ for all). Patients who reported chest tightness $(\mathrm{n}=75)$ had lower FEFs than patients who did not $(\mathrm{P}<.001$ for all). In subjects with chest tightness, the combination of FEF50\% or FEF $25 \%-75 \%$ with EOS also increased the AUCs substantially, to 0.815 and 0.816 , respectively ( $\mathrm{P}<.001$ for all versus the univariate AUCs). Conclusion: FENO combined with FEF50\% and FEF25\%-75\% predict BHR in patients with normal FEV1. FEF25\%-75\%. FEF50\%, or FEF25\%-75\% together with EOS also can potentially suggest asthma in patients with chest tightness.
\end{abstract}

\section{Introduction}

Bronchial asthma (asthma) is a chronic inflammatory airway disease affecting the entire bronchial tree from the large to the small airways ( $<2 \mathrm{~mm}$ diameter). ${ }^{1}$ The diagnosis is based on recurrent symptoms of dyspnea, cough, wheeze, and chest tightness, as well as reversible airway limitation or bronchial hyperresponsiveness $(\mathrm{BHR}) .^{2}$ In nearly $90 \%$ of asthmatic patients with normal forced expiratory volume in 1 second $\left(\mathrm{FEV}_{1}\right)$, also known as mild asthma, the bronchial dilation test is negative, so the provocation test is important for confirming or excluding asthma. However, many hospitals do not perform provocation tests because they are expensive, time-consuming, and entail a risk of severe bronchospasm. ${ }^{2}$ Therefore, additional ways are needed to predict BHR safely and to detect patients with mild asthma as early as possible in order to relieve their symptoms and prevent the development of chronic inflammation and airway remodeling.

Small-airway dysfunction exists in mild asthma patient, evaluated by a variety of spirometry and IOS measurements. $\mathrm{FEF}_{25 \%-75 \%}$ and $\mathrm{FEF}_{50 \%}$ are widely used for assessing small-airway function. ${ }^{3-8}$ Impulse oscillom- 
etry (IOS) may also reliably reflect small-airway function and predict clinical asthma outcomes and BHR..$^{9-13}$ FEV in 3 seconds $\left(\mathrm{FEV}_{3}\right) / \mathrm{FVC}$ is influenced by the airflow velocity in both the central and peripheral airway, normally $95 \%$ or greater in adults. ${ }^{14-16}$

In our previous study of patients with chronic cough, patients with BHR had higher fractional exhaled nitric oxide (FENO), a higher percentage of eosinophils in blood (EOS\%), and lower forced expiratory flow between $25 \%$ and $75 \%\left(\mathrm{FEF}_{25 \%-75 \%}\right)$ than patients without BHR. ${ }^{3}$ The combination of $\mathrm{FEF}_{25 \%-75 \%}$ and FENO increased the area under the curve (AUC) for BHR diagnosis substantially compared with FENO alone. In that study, $\mathrm{FEF}_{25 \%-75 \%}<78.5 \%$ and FENO $>43$ ppb strongly predicted positive BHR in Chinese patients with chronic cough.

In the current study, we used FEFs, peripheral airway resistance as the difference between 5 and $20 \mathrm{~Hz}$ (R5-R20), reactance at $5 \mathrm{~Hz}$ (X5), resonant frequency (Fres), FEV $3 / \mathrm{FVC}, \mathrm{FENO}, \mathrm{EOS}$, and EOS\% alone or in combination, as potential predictive variables for the presence of BHR, and extended our cross-sectional study to patients with $\mathrm{FEV}_{1}$ [?] $80 \%$ predicted who had more than 1 typical symptom of asthma, such as variable cough, dyspnea, wheeze, and chest tightness, to confirm the predictive value of small-airway function tests, FENO, and EOS for BHR.

\section{Methods}

\section{Study design and subject selection}

A retrospective cross-section of diagnostic data was collected at the initial visit of adult patients with recurrent variable symptoms of dyspnea, cough, wheeze, or chest tightness of at least 8 weeks' duration who were referred to the Pulmonary Outpatient Clinic of Shanghai General Hospital (China). The patients had to undergone a peripheral blood test, spirometry, ${ }^{17}$ FENO (NIOX MINO, Aerocrine AB, Solna, Sweden), ${ }^{13}$ methacholine $(\mathrm{MCH})$, and high-resolution computerized tomography (HRCT, GE Medical System; slice thickness $0.625 \mathrm{~mm}$ ) from September 2016 to January 2020. The MCH bronchoprovocation was performed with a Jaeger APS Pro system using a Medic-Aid sidestream nebulizer and doubling doses of MCH (0.015 to $0.48 \mathrm{mg}$ ) following the American Thoracic Society/European Respiratory Society recommendations. ${ }^{14}$

Additional inclusion criteria were age 18-75 years, normal HRCT results, and predicted $\mathrm{FEV}_{1}$ of $80 \%$ or greater with spirometric measurement.

Subjects were excluded if they had had respiratory tract infections in the past 8 weeks; peripheral blood test indicating abnormal hemoglobin, platelets or neutrophils; use of montelukast, long-acting $\beta_{2}$-agonists, theophylline, anticholinergic agents, or an inhaled or oral corticosteroid in the previous 4 weeks; or having concomitant severe systemic diseases. Patients who had more than a 10 pack-year smoking history, who currently smoked, or who had quit less than 2 years earlier were also excluded.

Descriptive characteristics, clinical history, results of bronchial provocation tests, spirometry, FENO, IOS (Jaeger Co, Hoechberg, Germany), ${ }^{18}$ EOS, and EOS\% were reviewed and analyzed. The FVC, FEV 1 , peak expiratory flow, $\mathrm{FEF}_{25 \%}, \mathrm{FEF}_{50 \%}, \mathrm{FEF}_{75 \%}$, and $\mathrm{FEF}_{25 \%-75 \%}$ were expressed as percentages of predicted values. $\mathrm{FEV}_{1} / \mathrm{FVC}$ and $\mathrm{FEV}_{3} / \mathrm{FVC}$ were expressed as the ratios of the absolute values of the variables. Small-airway dysfunction was identified if 2 of $\mathrm{FEF}_{50 \%}, \mathrm{FEF}_{75 \%}$, and $\mathrm{FEF}_{25 \%-75 \%}$ were lower than $80 \%$. IOS variables R5, R20, R5-R20, X5, and Fres were also collected. For bronchial provocation tests, the provocative dose causing a $20 \%$ fall in $\mathrm{FEV}_{1}\left(\mathrm{PD}_{20}\right)$ was recorded, and $\mathrm{BHR}$ was defined as present if $\mathrm{PD}_{20}$ was [?]0.48 mg. Associations of $\mathrm{PD}_{20}$ and FENO, EOS, EOS\%, FEFs, and IOS were analyzed in patients positive for BHR.

The ethics committee of Shanghai General Hospital, Shanghai Jiao Tong University, approved the protocol, and a waiver of informed consent was given for our study (number 2017KY159).

\section{Statistical analysis}

Analyses were performed with SPSS software version 19.0 (SPSS Inc, Chicago, Illinois, USA), except for the ROC contrast estimation, ROC contrast test, and 80/20 split-sample cross-validation, which were performed 
with SAS Proc LOGISTIC version 9.4 (SAS Institute Inc., Cary, NC, USA). Normality of distribution was checked with the Kolmogorov-Smirnov test. Normally distributed data were expressed as mean \pm standard deviation (SD) or 95\% Confidence interval (CI). Non-normally distributed data were expressed as median and interquartile ranges (IQR). The coefficient of variance (CV) was calculated for each continuous variable. Fisher's exact test was to analyze intergroup differences for discontinuous variables. The Mann-Whitney test was performed for the intergroup comparisons for continuous variables. The association between different variables was decided by Spearman correlation, since the Gaussian Approximation was proved for analyzed variables.

The 2 independent variables of interest were assessed by their marginal effects on the response in a logistic regression model. The prediction performance of each variable was measured as the AUC of the ROC derived from the logistic regression models. Furthermore, a multiple logistic model of the 2 variables was fitted, and the resultant AUC of this multiple logistic model was used as a measure of the joint prediction performance. We use the chi-square test proposed by DeLong et al to determine whether the multiple logistic model would significantly improve the prediction performance, defined as the AUC, relative to the marginal models. ${ }^{19}$

We used MCH bronchial provocation tests as the gold standard for defining BHR. The optimal value of the single measurement giving the highest sum of BHR diagnostic sensitivity and specificity was used as a cut-off value. ${ }^{20-21}$ Positive predictive values (PPV), negative predictive values (NPV), and percentages correctly classified (PCC) were calculated for each cut-off value. ${ }^{22-23}$ The corresponding odds ratios, CI, and $P$ values were also calculated.

Continuous variables were converted to dichotomous-state variables on the basis of the cut-off values. Subsequently, ROC curves were determined for the joint models with the dichotomous-state variables.

We constructed and examined all models to predict BHR with repeated five-fold cross-validation ( 5 repeats), which partitions the original sample into 5 disjoint subsets, uses 4 of those subsets in the training process, and then makes predictions about the remaining subset. The average AUC of 5 different cross-validation models and the whole-model AUC using the entire data set were calculated. The Error Rate equals abs (Average AUC - Whole Model AUC)/(Whole Model AUC). Accurate classification was also calculated for the test subset.

The threshold for statistical significance for all analyses was set at $P<.05$.

\section{Results}

\section{Baseline characteristics}

Clinical data from 692 adults were ultimately included. Bronchial provocation tests were positive in 170 patients and negative in 522 patients. Baseline demographics categorized by bronchial provocation test positivity are shown in Table 1 . There were no significant differences in age, sex, smoking history, or body mass index (BMI) between the 2 groups. Subjects with BHR had lower $\mathrm{FEV}_{1}, \mathrm{FEV}_{1} / \mathrm{FVC}$, and $\mathrm{FEV}_{3} / \mathrm{FVC}$ $\left(P\right.$ [?] .001 for all). All FEF values, alone or as ratios of their predicted value to that of $\mathrm{FEV}_{1}$ predicted value, were significantly lower in subjects with BHR than without BHR $(P<.001$ for all). Small-airway dysfunction was identified in 104 patients with BHR (61.17\%)and 132 patients without BHR (25.29\%) $(P$ $<.001)$.

Significantly higher levels of IOS variables (R5-R20, X5, and Fres) were observed in the BHR group $(P<$ .001 for all). Furthermore, FENO values, EOS counts, and EOS\% were also dramatically higher in the BHR group $(P<.001$ for all) (Table 1$)$.

Mean values of $\mathrm{FEV}_{1}, \mathrm{FEV}_{1} / \mathrm{FVC}, \mathrm{FEF}_{50 \%}, \mathrm{FEF}_{75 \%}$ and $\mathrm{FEF}_{25 \%-75 \%}$ were lower in subjects with chest tightness $(\mathrm{n}=75)$ compared with those without this symptom $(P=.009, .008, .003,<.001$, and .002 , respectively). FENO values, EOS counts, and EOS\% values were higher in subjects with than without chest tightness $(P=.012, .001, .003$, and .014 , respectively).

\section{Correlation between $\mathrm{PD}_{20}$ and FENO, EOS counts, EOS\%, FEFs and R5-R20}


FENO, $\mathrm{FEF}_{25 \%}, \mathrm{FEF}_{50 \%}, \mathrm{FEF}_{75 \%}$, and $\mathrm{FEF}_{25 \%-75 \%}$ were weakly correlated with $\mathrm{PD}_{20}$ by Spearman analysis (Table 2). No significant correlation between $\mathrm{PD}_{20}$ and $\mathrm{FEV}_{3} / \mathrm{FVC}$, EOS counts, EOS\%, R5-R20, X5, or Fres was found. There was no difference in $\mathrm{PD}_{20}$ between subjects with chest tightness $(0.065 ; \mathrm{IQR}, 0.220)$ and those without this symptom (0.089; IQR, $0.349 ; P=0.764)$.

\section{Diagnostic accuracy of single variables used for predicting BHR}

We created ROC curves to evaluate the ability of many of the variables to predict positive BHR. In the spirometry measurements, the 2 largest AUCs for a positive BHR diagnosis were 0.763 for $\mathrm{FEF}_{25 \%-75 \%}$ and 0.762 for $\mathrm{FEF}_{50 \%}$ (Table 3). The $\mathrm{FEV}_{1} / \mathrm{FVC}$, EOS\%, EOS, and IOS measurements did not give high AUCs for positive BHR diagnosis.

In patients with chest tightness, the AUCs for positive BHR diagnosis were $\mathrm{FEF}_{50 \%} 0.751$ (95\% CI, 0.637 0.864), $\mathrm{FEF}_{75 \%} 0.812$ (95\% CI, 0.708 - 0.916), $\mathrm{FEF}_{25 \%-75 \%} 0.763$ (95\% CI, 0.651 - 0.875), FENO 0.731 (95\% CI, $0.607-0.855)$, and EOS counts 0.706 (95\% CI, $0.580-0.832)$.

Diagnostic accuracy of small-airway function variables combined with FENO andinternal crossvalidation of the final models

To determine whether combining measurements would improve BHR prediction, we repeated the ROC analyses for spirometry measurements combined with FENO. The AUC of $\mathrm{FEF}_{50 \%}$ combined with FENO was 0.845 (95\% CI, 0.812-0.878), which was significantly higher than the AUC of univariate $\mathrm{FEF}_{50 \%}(P<$ .001) (Table 4 and Figure 1). Similarly, the other spirometry measurements also had higher AUCs when combined with FENO than they did alone (Table 4) NPV was [?]85.45\% for all of the combinations.

We then transformed the continuous variables into binary variables according to the cut-off values shown in Tables and reanalyzed the mentioned above ROC curves. The AUCs of $\mathrm{FEF}_{50 \%}$ and $\mathrm{FEF}_{25 \%-75 \%}$ combined with FENO remained high (Figure 2).

In patients with chest tightness, the $\mathrm{AUCs}$ of $\mathrm{FEF}_{50 \%}, \mathrm{FEF}_{75 \%}$, and $\mathrm{FEF}_{25 \%-75 \%}$ combined with FENO were 0.880 (95\% CI, 0.806-0.954), 0.892 (95\% CI, 0.812-0.972), and 0.884 (95\% CI, 0.805-0.934), respectively (Table 5).

The error rates between the average AUC of 5 different cross-validation models and the whole-model AUC using the entire data set were lower than 0.05 for all chosen variables, indicating that the data model has stable predictive ability for different data sets.

\section{Diagnostic accuracy of small-airway function variables combined with EOS in blood}

We repeated the ROC analyses for spirometry measurements $\left(\mathrm{FEF}_{50 \%}, \mathrm{FEF}_{25 \%-75 \%}, \mathrm{FEV}_{1} / \mathrm{FVC}\right)$ combined with EOS (Table 6). The AUCs of the combined models were between 0.734 and 0.786 , and all had NPV [?] $85.08 \%$. The AUCs of FEFs combined with EOS were higher in patients with chest tightness than in the population as a whole $\left(0.815,0.845\right.$, and 0.816 , for $\mathrm{FEF}_{50 \%}, \mathrm{FEF}_{75 \%}$, and $\mathrm{FEF}_{25 \%-75 \%}$, respectively; Table $5)$.

\section{Discussion}

Early diagnosis of asthma is very important, not only to relieve the patient's symptoms, but also to prevent the development of chronic inflammation and airway remodeling. However, early diagnosis is difficult because patients need to satisfy the 2 criteria of variable symptoms and air-flow limitation. This is especially true for mild asthma, which is often undiagnosed because $\mathrm{FEV}_{1}$ is normal and the bronchodilation test has a high false-negative rate. Our data indicating that small-airway dysfunction is present in asthmatic patients with $\mathrm{FEV}_{1}$ [?] $80 \%$ predicted may help to provide an early diagnosis in patients with mild asthma. Measurements of small-airway function, including $\mathrm{FEF}_{50 \%}$ and $\mathrm{FEF}_{25 \%-75 \%}$, combined with measures of airway inflammation (FENO or EOS counts) provided the best prediction of positive BHR diagnosis in subjects who had both typical asthma-like symptoms and $\mathrm{FEV}_{1}$ [?] $80 \%$ predicted. 
Type II airway inflammation increases both EOS counts and FENO, which are used in asthma diagnosis and the therapeutic response's evaluation of anti-asthma. ${ }^{24,25}$ Our data also showed that the levels of both EOS and FENO were higher in the BHR-positive group. Previous studies in guinea pigs have shown that NO may itself contribute to BHR, by increasing plasma exudation via its vasodilator effect and by its transformation into peroxynitrite, which induces BHR. ${ }^{26}$ Furthermore, in our study, a weak correlation between FENO and $\mathrm{PD}_{20}$ in patients with positive BHR was observed $(r=-0.266, P=.0005)$, suggesting that FENO is valuable in predicting BHR, which was also noted by Jatakanon et al. ${ }^{27}$

Currently, FENO is particularly helpful in ruling out asthma. Its cut-off value for predicting asthma ranged from 10.5 to $64 \mathrm{ppb}$ in different studies. ${ }^{28} \mathrm{FENO}<30 \mathrm{ppb}$ has a high specificity (87\%) and NPV $(93 \%)$ for excluding asthma from untreated nonsmoking adults with chronic cough. ${ }^{29}$ Schleich et al showed that FENO $>34 \mathrm{ppb}$ had a low predictive value $(\mathrm{AUC}=0.62)$ for predicting BHR in patients with suspected asthma ${ }^{30}$ Schneider et al illustrated that, in their sample as a whole, asthma could be ruled in at FENO > $71 \mathrm{ppb}(\mathrm{PPV}, 80 \%)$ and ruled out at FENO [?] $9 \mathrm{ppb}$ (NPV, 82\%), with an AUC of $0.656 .{ }^{31}$ Importantly, when patients with neutrophilic inflammation were omitted, the AUC was 0.745 and asthma could be ruled in at FENO > $31 \mathrm{ppb}$ (PPV, 82\%) and ruled out at FENO [?] $12 \mathrm{ppb}$ (NPV, 81\%). ${ }^{31}$ Our present study showed that FENO > 41 ppb has a sensitivity of $65.29 \%$, specificity of $78.16 \%$, PPV of $49.33 \%$, and NPV of $87.37 \%$. The AUC for predicting BHR was 0.748, regardless of the inflammatory type, which is similar to the AUC from Schneider et al when patients with neutrophilic inflammation were omitted.

In our current study, patients positive for BHR, but with $\mathrm{FEV}_{1}$ in the normal range, had abnormal values of small-airway function variables, obtained with spirometry and IOS. Two-thirds of asthmatic patients with $\mathrm{FEV}_{1}$ [?] 80\% predicted had small-airway dysfunction, and patients with small-airway dysfunction exhibit a greater likelihood of $\mathrm{BHR}$. $\mathrm{FEF}_{50 \%}, \mathrm{FEF}_{75 \%}$, and $\mathrm{FEF}_{25 \%-75 \%}$ were weakly correlated with $\mathrm{PD}_{20}$. This might indicate that small-airway dysfunction could be a forerunner of decreased $\mathrm{FEV}_{1}$ and could be used to detect early disease.

We found the 2 most valuable spirometric variables for predicting $\mathrm{BHR}$ were $\mathrm{FEF}_{25 \%-75 \%}$ (AUC $=0.763$ ) and $\mathrm{FEF}_{50 \%}(\mathrm{AUC}=0.762)$ (Table 3$)$. The $2 \mathrm{FEFs}$ were strongly correlated and had equivalent value in predicting BHR. However, because both produced AUC $<0.80$, using them singly would be insufficient for predicting BHR in patients with suspected asthma. Thus, we combined the FEFs with FENO or EOS counts to enhance their predictive value for BHR diagnosis. The AUCs of FEFs combined with FENO were significantly higher than those of the univariate AUCs. This suggests that FEFs combined with FENO (2 noninvasive and convenient measurements) can improve the prediction of BHR diagnosis. The cut-off values had certain difference among different studies possibly because we included patients with mild asthma-like symptoms and normal $\mathrm{FEV}_{1}$, who had higher FEF levels than those with more severe symptoms. ${ }^{4}, 32-34$

One main limitation of FEF is that it depends on FVC and lung capacity. ${ }^{35,36}$ In contrast to $\mathrm{FEV}_{1}$, $\mathrm{FEF}_{25 \%-75 \%}$ is not normalized to $\mathrm{FVC}$ when assessing air-flow obstruction. Therefore, $\mathrm{FEF}_{25 \%-75 \%}$ could be artificially low in individuals with restrictive lung or chest bellows disease (e.g., obesity) and could therefore overdiagnose asthma. In our study, mean BMI and FVC were in the normal range $\left(23.37+-3.477 \mathrm{~kg} / \mathrm{m}^{2}\right.$ and $101.5 \%+-12 \%$, respectively), and neither variable differed between groups. ${ }^{36,37}$ Most importantly, all patients in the study had undergone HRCT, therefore guaranteeing that restrictive lung diseases or obesity were excluded and minimizing the possibility of overdiagnosis of asthma in our patients. Furthermore, IOS is a noninvasive alternate test that is not affected by expiratory flow and is more physiologically relevant than spirometry. ${ }^{38,39}$ We evaluated the ability of IOS measurement to assess small-airway function and to predict BHR. In our study, R5-R20 alone exhibited poor predictive value for BHR diagnosis, and the AUC was still lower than 0.80 when we combined R5-R20 and FENO. This finding suggests that when combined with FENO, FEFs provide better value than R5-R20 for predicting BHR even though they are less physiologically relevant.

Chest tightness is a symptom of asthma that is more likely reflects muscle tightness or physical difficulty with moving air that is sensed through proprioception and not through pain pathways. ${ }^{40-42}$ In asthmatic patients with normal $\mathrm{FEV}_{1}$ in our study, the most frequent complaints were chest tightness and cough rather than 
wheeze or dyspnea. Relevant clinical subtypes of asthma, "chest tightness variant asthma" 43 and "chest pain variant asthma" 40,44 have been described in the medical literature. Asthmatic patients who only complain of chest tightness are easily misdiagnosed in clinical practice. We found that decreases of $\mathrm{FEV}_{1}, \mathrm{FEV}_{1} / \mathrm{FVC}$, $\mathrm{FEF}_{25 \%}, \mathrm{FEF}_{50 \%}, \mathrm{FEF}_{75 \%}$, and $\mathrm{FEF}_{25 \%-75 \%}$ were more serious in subjects with than without chest tightness, indicating that small-airway dysfunction may be involved in the mechanism of chest tightness. The joint model of small-airway function variables $\left(\mathrm{FEF}_{50 \%}, \mathrm{FEF}_{75 \%}\right.$, or $\left.\mathrm{FEF}_{25 \%-75 \%}\right)$ and $\mathrm{FENO}$ gave particularly high predictive values for BHR in subjects with chest tightness (all of the AUCs [?] 0.880). In addition, the joint model of EOS with small-airway function variables $\left(\mathrm{FEF}_{50 \%}, \mathrm{FEF}_{75 \%}\right.$, or $\left.\mathrm{FEF}_{25 \%-75 \%}\right)$ was highly predictive of BHR in subjects with chest tightness (all of the AUCs [?] 0.815), which it was not for the population as a whole. Since the cost of peripheral blood cells count is much cheaper than FENO, these tests may provide very economic alternatives for predicting BHR in suspected asthmatics, especially in primary hospitals. The diagnosis of asthma should be strongly considered in patients with lower FEFs, high FENO or high EOS counts, and the symptom of chest tightness.

The progressive statistical design of this study consisted of several steps. First, the possible influencing variables were found from a Mann-Whitney test. Then, the correlation between the relevant variables and $\mathrm{PD}_{20}$ was determined with Spearman analysis. Through the analysis of AUC, the predictive value of those variables was further verified. The repeatability of our data calculation was shown by an $80 / 20$ split-sample cross- validation. The AUCs in the validation sample were close to those in the whole model.

To overcome some limitations of our current study, larger-scale and multicenter prospective clinical trials should be performed to ensure the integrity of the inspection results.

In conclusion, asthmatic patients suffer from small-airway dysfunction, even though their $\mathrm{FEV}_{1}$ is within the normal range. Patients with small-airway dysfunction exhibit an increased likelihood of having BHR. In order to improve the diagnosis rate of mild asthma and relieve patients' symptoms as early as possible, we combined 2 simple and noninvasive methods - small-airway function tests and FENO to improve the diagnosis rate of mild asthma. The likelihood of BHR strongly increased with $\mathrm{FEF}_{25 \%-75 \%}<84.4 \%, \mathrm{FEF}_{50 \%}$ $<76.8 \%$, and FENO $>41$ ppb. $\mathrm{FEV}_{25 \%-75 \%}$ and $\mathrm{FEF}_{50 \%}$, derived from spirometry, could be combined with FENO to diagnose asthma in patients with normal $\mathrm{FEV}_{1}$ and symptoms suggestive of asthma, allowing the patient to forego $\mathrm{MCH}$ challenge testing for the diagnosis. $\mathrm{FEF}_{25 \%-75 \%}$, or $\mathrm{FEF}_{50 \%}$ combined with EOS can also be a very economic method to predict BHR in suspected asthma subjects with chest tightness.

\section{Acknowlegements}

The study was supported by National Natural Science Foundation of China (Grant No. 81873402, and 81800020); Appropriate technique application Program of Shanghai Municipal Health System (Grant No.2019SY042); Program of Shanghai Municipal Health System (Grant No.201740039).

\section{Conflict of interest}

All authors have reported that no potential conflicts of interest exist with any companies/organizations whose products or services may be discussed in this article.

\section{Author contributions}

Wuping Bao, Xue Zhang, and Min Zhang conceived of and designed the entire study.

Xue Zhang, Huijuan Hao and Chengjian Lv contributed to data collection.

Wuping Bao, Luhong Bao, Yishu Xue, Lei Han, Xue Zhang, and Xin Zhou were involved in interpreting spirometric assessments, bronchial provocation tests, IOS measurements, and FENO data.

Wuping Bao, Xue Zhang, Junfeng Yin, and Zhixuan Huang performed the statistical analyses.

Wuping Bao and Xue Zhang wrote the manuscript, supervised by Min Zhang.

All authors critically reviewed and approved the final version. 
All authors agreed to be accountable for all aspects of the work in ensuring that questions related to the accuracy or integrity of any part of the work are appropriately investigated and resolved.

\section{References}

1. Lipworth B, Manoharan A, Anderson W. Unlocking the quiet zone: the small airway asthma phenotype. Lancet Respir Med. 2014;2(6):497-506.

2. Popa V. ATS guidelines for methacholine and exercise challenge testing. Am J Respir Crit Care Med. 2001;163(1):292-293.

3. Bao W, Zhang X, Lv C, et al. The Value of Fractional Exhaled Nitric Oxide and Forced Mid-Expiratory Flow as Predictive Markers of Bronchial Hyperresponsiveness in Adults with Chronic Cough. J Allergy Clin Immunol Pract. 2018;6(4):1313-1320.

4. Drewek R, Garber E, Stanclik S, Simpson P, Nugent M, Gershan W. The FEF25-75 and its decline as a predictor of methacholine responsiveness in children. J Asthma. 2009;46(4):375-381.

5. van der Wiel E, Postma DS, van der Molen T, Schiphof-Godart L, Ten Hacken NH, van den Berge M. Effects of small airway dysfunction on the clinical expression of asthma: a focus on asthma symptoms and bronchial hyper-responsiveness. Allergy. 2014;69(12):1681-1688.

6. Lang A, Carlsen KH, Haaland G, et al. Severe asthma in childhood: assessed in 10 year olds in a birth cohort study. Allergy. 2008;63(8):1054-1060.

7. Backer V, Mortensen J. Distribution of radioactive aerosol in the airways of children and adolescents with bronchial hyper-responsiveness. Clin Physiol. 1992;12(5):575-585.

8. Pliss LB, Ingenito EP, Ingram RH Jr. Responsiveness, inflammation, and effects of deep breaths on obstruction in mild asthma. J Appl Physiol (1985). 1989;66(5):2298-2304.

9. Shi Y, Aledia AS, Galant SP, George SC. Peripheral airway impairment measured by oscillometry predicts loss of asthma control in children. J Allergy Clin Immunol. 2013;131(3):718-723.

10. Manoharan A, von Wilamowitz-Moellendorff A, Morrison A, Lipworth BJ. Effects of formoterol or salmeterol on impulse oscillometry in patients with persistent asthma. J Allergy Clin Immunol. 2016;137(3):727-33.e1.

11. Arıkoglu T, Unlu A, Yıldırım DD, Kuyucu S. The airway hyperresponsiveness to methacholine may be predicted by impulse oscillometry and plethysmography in children with well-controlled asthma. J Asthma. 2018;55(11):1166-1173.

12. Wagner EM, Liu MC, Weinmann GG, Permutt S, Bleecker ER. Peripheral lung resistance in normal and asthmatic subjects. Am Rev Respir Dis. 1990;141(3):584-588.

13. Dweik RA, Boggs PB, Erzurum SC, et al. An official ATS clinical practice guideline: interpretation of exhaled nitric oxide levels (FENO) for clinical applications. Am J Respir Crit Care Med. 2011;184(5):602-615.

14. Madan K, Hadda V, Khilnani GC, Guleria R. Isolated reduction of the FEV3/FVC ratio as an indicator of mild airflow obstruction. Chest. 2014;145(3):662.

15. Piorunek T, Kostrzewska M, Stelmach-Mardas M, et al. Small Airway Obstruction in Chronic Obstructive Pulmonary Disease: Potential Parameters for Early Detection. Adv Exp Med Biol. 2017;980:75-82.

16. Morris ZQ, Coz A, Starosta D. An isolated reduction of the FEV3/FVC ratio is an indicator of mild lung injury. Chest. 2013;144(4):1117-1123.

17. Coates AL, Wanger J, Cockcroft DW, et al. ERS technical standard on bronchial challenge testing: general considerations and performance of methacholine challenge tests. Eur Respir J. 2017;49(5):1601526.

18. Wagner EM, Liu MC, Weinmann GG, Permutt S, Bleecker ER. Peripheral lung resistance in normal and asthmatic subjects. Am Rev Respir Dis. 1990;141(3):584-588.

19. DeLong ER, DeLong DM, Clarke-Pearson DL. Comparing the Areas under Two or More Correlated Receiver Operating Characteristic Curves: A Nonparametric Approach. Biometrics. 1988; 44(3):837845 .

20. Altman DG, Bland JM. Diagnostic tests 2: Predictive values. BMJ. 1994;309(6947):102.

21. Youden WJ. Index for rating diagnostic tests. Cancer. 1950 Jan;3(1):32-35.

22. Thornbury JR, Fryback DG, Edwards W. Likelihood ratios as a measure of the diagnostic usefulness 
of excretory urogram information. Radiology. 1975;114(3):561-565.

23. Hung J, Chaitman BR, Lam J, et al. A logistic regression analysis of multiple noninvasive tests for the prediction of the presence and extent of coronary artery disease in men. Am Heart J. 1985;110(2):460469.

24. Castro M, Corren J, Pavord ID, et al. Dupilumab Efficacy and Safety in Moderate-to-Severe Uncontrolled Asthma. N Engl J Med. 2018;378(26):2486-2496.

25. Beretta C, Rifflart C, Evrard G, Jamart J, Thimpont J, Vandenplas O. Assessment of eosinophilic airway inflammation as a contribution to the diagnosis of occupational asthma. Allergy. 2018;73(1):206213.

26. Sadeghi-Hashjin G, Folkerts G, Henricks PA, et al. Peroxynitrite induces airway hyperresponsiveness in guinea pigs in vitro and in vivo. Am J Respir Crit Care Med. 1996;153(5):1697-1701.

27. Jatakanon A, Lim S, Kharitonov SA, Chung KF, Barnes PJ. Correlation between exhaled nitric oxide, sputum eosinophils, and methacholine responsiveness in patients with mild asthma. Thorax. 1998;53(2):91-95.

28. Song WJ, Kim HJ, Shim JS, et al. Diagnostic accuracy of fractional exhaled nitric oxide measurement in predicting cough-variant asthma and eosinophilic bronchitis in adults with chronic cough: A systematic review and meta-analysis. J Allergy Clin Immunol. 2017;140(3):701-709.

29. Chatkin JM, Ansarin K, Silkoff PE, et al. Exhaled nitric oxide as a noninvasive assessment of chronic cough. Am J Respir Crit Care Med. 1999;159(6):1810-1813.

30. Schleich FN, Asandei R, Manise M, Sele J, Seidel L, Louis R. Is FENO50 useful diagnostic tool in suspected asthma?. Int J Clin Pract. 2012;66(2):158-165.

31. Schneider A, Schwarzbach J, Faderl B, Welker L, Karsch-Völk M, Jörres RA. FENO measurement and sputum analysis for diagnosing asthma in clinical practice. Respir Med. 2013;107(2):209-216.

32. Cirillo I, Klersy C, Marseglia GL, et al. Role of FEF $25 \%-75 \%$ as a predictor of bronchial hyperreactivity in allergic patients. Ann Allergy Asthma Immunol. 2006;96(5):692-700.

33. He L, Wei M, Luo J, et al. Re-evaluation of the diagnostic value of fractional exhaled nitric oxide \& its impact in patients with asthma. Indian J Med Res. 2018;148(4):441-448.

34. Feng-Jia C, Xin-Yan H, Geng-Peng L, Yang-Li L, Can-Mao X. Validity of fractional exhaled nitric oxide and small airway function indices in diagnosis of cough-variant asthma. J Asthma. 2018;55(7):750-755.

35. Pellegrino R, Viegi G, Brusasco V, et al. Interpretative strategies for lung function tests. Eur Respir J. 2005;26(5):948-968.

36. Lee H, Chang B, Kim K, et al. Clinical Utility of Additional Measurement of Total Lung Capacity in Diagnosing Obstructive Lung Disease in Subjects with Restrictive Pattern of Spirometry. Respir Care. 2016;61(4):475-482.

37. Forno E, Han YY, Mullen J, Celedón JC. Overweight, Obesity, and Lung Function in Children and Adults-A Meta-analysis. J Allergy Clin Immunol Pract. 2018;6(2):570-581.e10.

38. Marotta A, Klinnert MD, Price MR, Larsen GL, Liu AH. Impulse oscillometry provides an effective measure of lung dysfunction in 4-year-old children at risk for persistent asthma. J Allergy Clin Immunol. 2003;112(2):317-322.

39. Heijkenskjöld Rentzhog C, Janson C, Berglund L, et al. Overall and peripheral lung function assessment by spirometry and forced oscillation technique in relation to asthma diagnosis and control. Clin Exp Allergy. 2017;47(12):1546-1554.

40. Farr RS, Kopetzky MT, Spector SL, Hurewitz DS. Asthma without wheezing. Chest. 1973;63:Suppl:64S-68S.

41. Global Initiative for Asthma. 2016 GINA Report, Global Strategy for Asthma Management and Prevention. Available at:http://ginasthma.org/2016-gina-reportglobal-strategy-for-asthma-management-andprevention. Accessed November 23, 2016.

42. Taniguchi H, Furuse H, Nakanishi Y, et al. Bronchial biopsy and reactivity in patients with chest tightness relieved with bronchodilator. J Asthma. 2017;54(5):479-487.

43. Shen H, Hua W, Wang P, Li W. A new phenotype of asthma: chest tightness as the sole presenting manifestation. Ann Allergy Asthma Immunol. 2013;111(3):226-227. 
44. Taniguchi H, Kanbara K, Hoshino K, Izumi S. Chest pain relieved with a bronchodilator or other asthma drugs. Allergol Int. 2009;58(3):421-427.

Table 1. Demographic data, spirometric variables, IOS variables, and values for FENO and peripheral eosinophils of patients with positive or negative bronchial provocation tests

\begin{tabular}{|c|c|c|c|c|}
\hline Variables & $\begin{array}{l}\text { CV for all subjects } \\
(\%)\end{array}$ & $\begin{array}{l}\text { Positive bronchial } \\
\text { provocation test }\end{array}$ & $\begin{array}{l}\text { Negative bronchial } \\
\text { provocation test }\end{array}$ & $P$ value \\
\hline $\mathrm{n}$ & - & 170 & 522 & - \\
\hline Age, years ${ }^{+}$ & 33.79 & $43.90(14.56)$ & $43.80(14.90)$ & 0.980 \\
\hline Male, n (\%) & - & $53(31.18 \%)$ & $203(38.89 \%)$ & 0.082 \\
\hline BMI, $\mathrm{kg} / \mathrm{m}^{2+}$ & 14.88 & $22.94(2.99)$ & $23.51(3.61)$ & 0.075 \\
\hline $\begin{array}{l}\text { Past smoking } \\
\text { history (n / \%) }\end{array}$ & - & $31(18.24)$ & $97(18.58)$ & .204 \\
\hline $\begin{array}{l}\text { FVC, } \% \\
\text { predicted }^{+}\end{array}$ & 11.82 & $101.10(10.85)$ & $101.60(12.36)$ & 0.993 \\
\hline $\begin{array}{l}\mathrm{FEV}_{1}, \% \\
\text { predicted }^{+}\end{array}$ & 11.95 & $99.33(11.01)$ & $105.50(12.49)$ & $<.001$ \\
\hline $\mathrm{FEV}_{1} / \mathrm{FVC}, \%^{+}$ & 6.72 & $82.55(5.51)$ & $86.87(5.45)$ & $<.001$ \\
\hline $\mathrm{FEV}_{3} / \mathrm{FVC}, \%+\S$ & 1.98 & $97.65(2.26)$ & $98.47(1.76)$ & 0.001 \\
\hline $\begin{array}{l}\mathrm{PEF}, \% \\
\text { predicted }^{+}\end{array}$ & 16.27 & $90.61(13.93)$ & $96.21(15.65)$ & $<.001$ \\
\hline $\begin{array}{l}\mathrm{FEF}_{25 \%}, \% \\
\text { predicted }^{+}\end{array}$ & 21.63 & $90.08(15.87)$ & $100.80(22.10)$ & $<.001$ \\
\hline $\begin{array}{l}\mathrm{FEF}_{50 \%}, \% \\
\text { predicted }^{+}\end{array}$ & 25.55 & $77.26(17.74)$ & $98.20(23.24)$ & $<.001$ \\
\hline $\begin{array}{l}\mathrm{FEF}_{75 \%}, \% \\
\text { predicted }^{+}\end{array}$ & 31.84 & $74.91(22.43)$ & $101.20(60.72)$ & $<.001$ \\
\hline $\begin{array}{l}\mathrm{FEF}_{25 \%-75 \%}, \% \\
\text { predicted }^{+}\end{array}$ & 25.51 & $75.95(17.64)$ & $97.01(22.76)$ & $<.001$ \\
\hline $\begin{array}{l}\text { Small-airway } \\
\text { dysfunction }\end{array}$ & - & 104 & 132 & $<.001$ \\
\hline $\begin{array}{l}\mathrm{R} 5-\mathrm{R} 20 \\
\mathrm{kPa} \cdot \mathrm{L}^{-1} \cdot \mathrm{s}^{+\mathrm{P}}\end{array}$ & 94.65 & $0.13(0.11)$ & $0.10(0.09)$ & $<.001$ \\
\hline $\mathrm{X} 5, \mathrm{kPa} \cdot \mathrm{L}^{-1} \cdot \mathrm{s}^{+\mathrm{P}}$ & 97.54 & $-0.12(0.10)$ & $-0.10(0.08)$ & $<.001$ \\
\hline Fres, $L^{-1} \cdot s^{+P}$ & 42.52 & $17.53(9.02)$ & $14.24(5.03)$ & $<.001$ \\
\hline FENO, $\mathrm{ppb}^{++}$ & 94.96 & $59(28-98)$ & $24(15-45)$ & $<.001$ \\
\hline $\begin{array}{l}\text { EOS in blood, } \% \\
++\end{array}$ & 95.46 & $\begin{array}{l}5.16(1.70- \\
7.73)\end{array}$ & $\begin{array}{l}3.37(1.20- \\
4.40)\end{array}$ & $<.001$ \\
\hline $\begin{array}{l}\text { EOS in blood, } \\
\text { cells } / \mu l^{++}\end{array}$ & 106.10 & $\begin{array}{l}370.6(120- \\
530)\end{array}$ & $\begin{array}{l}237.2(80- \\
302.5)\end{array}$ & $<.001$ \\
\hline $\mathrm{PD}_{20}, \mathrm{mg}^{++}$ & 130.68 & $0.079(.026-.369)$ & - & - \\
\hline
\end{tabular}

IOS, impulse oscillometry; FENO, fractional exhaled nitric oxide; CV, Coefficient of variance; BMI, body mass index; FVC, forced vital capacity; $\mathrm{FEV}_{1}$, forced expiratory volume in 1 second; $\mathrm{FEV}_{3}$, $\mathrm{FEV}$ in 3 seconds; $\mathrm{PEF}$, peak expiratory flow; $\mathrm{FEF}_{25 \%}$, forced expiratory flow at $25 \%$ of $\mathrm{FVC} ; \mathrm{FEF}_{50 \%}, \mathrm{FEF}$ at $50 \%$ of $\mathrm{FVC} ; \mathrm{FEF}_{75 \%}, \mathrm{FEF}$ at $75 \%$ of $\mathrm{FVC} ; \mathrm{FEF}_{25 \%-75 \%}$, FEF at $25 \%$ to $75 \%$ of FVC; EOS, eosinophils; ppb, parts per billion; $\mathrm{PD}_{20}$, provocative dose causing a $20 \%$ fall in $\mathrm{FEV}$ in the first second; $\mathrm{R} 5$, total airway resistance at $5 \mathrm{~Hz}$; R20, central airway resistance at $20 \mathrm{~Hz}$; R5-R20, peripheral airway resistance as the difference between 5 and $20 \mathrm{~Hz}$; X5, reactance at $5 \mathrm{~Hz}$; Fres, resonant frequency. 
Small-airway dysfunction was identified if 2 of the variables $\mathrm{FEF}_{50 \%}, \mathrm{FEF}_{75 \%}$ and $\mathrm{FEF}_{25 \%-75 \%}$ were lower than $80 \%$.

${ }^{+}$Mean $(\mathrm{SD})$ values.

${ }^{++}$Median (IQR) values

$\S \mathrm{n}=333,92$ for positive bronchial provocation, 241 for negative bronchial provocation

$\mathbb{I} \mathrm{n}=619,153$ for positive bronchial provocation, 466 for negative bronchial provocation

Bold font indicates statistical significance.

Table 2. Spearman correlation between $\mathrm{PD}_{20}$ and other variables in BHR-positive subjects.

\begin{tabular}{lllll}
\hline & $\mathbf{n}$ & $\mathbf{r}$ & $\mathrm{P}$ & $\mathbf{9 5 \%} \mathbf{C I}$ \\
\hline FENO & $\mathbf{1 7 0}$ & $-\mathbf{0 . 2 6 6}$ & $\mathbf{0 . 0 0 0 5}$ & $-\mathbf{0 . 4 0 4} \sim-\mathbf{0 . 1 1 6}$ \\
EOS counts & 170 & -0.054 & 0.481 & $-0.208^{\sim} 0.101$ \\
EOS\% & 170 & -0.039 & 0.609 & $-0.193^{\sim} 0.116$ \\
$\mathrm{FEF}_{25 \%}$ & $\mathbf{1 7 0}$ & $\mathbf{0 . 2 7 2}$ & $\mathbf{0 . 0 0 0 3}$ & $\mathbf{0 . 1 2 2} \sim \mathbf{0 . 4 0 9}$ \\
$\mathrm{FEF}_{50 \%}$ & $\mathbf{1 7 0}$ & $\mathbf{0 . 2 1 3}$ & $\mathbf{0 . 0 0 5}$ & $\mathbf{0 . 0 6 0} \sim \mathbf{0 . 3 5 6}$ \\
$\mathrm{FEF}_{75 \%}$ & $\mathbf{1 7 0}$ & $\mathbf{0 . 1 7 3}$ & $\mathbf{0 . 0 2 4}$ & $\mathbf{0 . 0 1 8} \sim \mathbf{0 . 3 1 9}$ \\
$\mathrm{FEF}_{25 \%}$-75\% & $\mathbf{1 7 0}$ & $\mathbf{0 . 2 2 9}$ & $\mathbf{0 . 0 0 3}$ & $\mathbf{0 . 0 7 7} \sim \mathbf{0 . 3 7 1}$ \\
$\mathrm{FEV}_{3} / \mathrm{FVC}$ & 92 & -0.016 & 0.881 & $-0.225^{\sim} 0.196$ \\
$\mathrm{R}_{-}$R20 & 153 & -0.026 & 0.754 & $-0.188^{\sim} 0.138$ \\
$\mathrm{X} 5$ & 153 & 0.115 & 0.158 & $-0.050 \sim 0.273$ \\
Fres & 153 & -0.064 & 0.433 & $-0.226 \sim 0.101$ \\
\hline
\end{tabular}

The abbreviations are as defined for Table 1

Bold font indicates statistical significance.

Table 3. Optimal cut-off values and other measures of usefulness for predicting bronchial hyperresponsiveness

\begin{tabular}{|c|c|c|c|c|c|c|c|c|c|}
\hline \multicolumn{2}{|c|}{ Characteristic } & $\begin{array}{l}\text { Cut-off } \\
\text { values }^{+}\end{array}$ & $\begin{array}{l}\text { Sensitivity } \\
\%\end{array}$ & $\begin{array}{l}\text { Specificity } \\
\%\end{array}$ & PPV \% & NPV \% & $\mathrm{PCC} \%$ & $\begin{array}{l}\text { Odds } \\
\text { ratio }\end{array}$ & $95 \% \mathrm{CI}$ \\
\hline $\begin{array}{l}\mathrm{FEV}_{1}, \\
\% \\
\text { predicted }\end{array}$ & 0.649 & 95.8 & 47.65 & 75.86 & 39.13 & 81.65 & 68.93 & 0.955 & $\begin{array}{l}(0.939, \\
0.971)\end{array}$ \\
\hline $\begin{array}{l}\mathrm{FEV}_{1} / \mathrm{FV} \\
\%\end{array}$ & Q., 713 & 84.67 & 66.47 & 67.62 & 40.07 & 86.10 & 67.34 & 0.867 & $\begin{array}{l}(0.837, \\
0.898)\end{array}$ \\
\hline $\begin{array}{l}\mathrm{FEV}_{3} / \mathrm{FVC} \\
\%\end{array}$ &, 0.616 & 99.06 & 67.39 & 51.87 & 34.83 & 80.65 & 56.16 & 0.817 & $\begin{array}{l}(0.726, \\
0.920)\end{array}$ \\
\hline $\begin{array}{l}\mathrm{FEF}_{25 \%}, \\
\% \\
\text { predicted }\end{array}$ & 0.656 & 103.8 & 84.12 & 41.38 & 31.85 & 88.89 & 51.88 & 0.973 & $\begin{array}{l}(0.963) \\
0.982)\end{array}$ \\
\hline $\begin{array}{l}\mathbf{F E F}_{50 \%}, \\
\% \\
\text { pre- } \\
\text { dicted }\end{array}$ & 0.762 & 76.8 & 58.82 & 80.46 & 49.50 & 85.71 & 75.14 & 0.950 & $\begin{array}{l}(0.939, \\
0.960)\end{array}$ \\
\hline $\begin{array}{l}\text { FEF }_{\mathbf{7 5 \%}}, \\
\% \\
\text { pre- } \\
\text { dicted }\end{array}$ & 0.745 & 81.4 & 66.47 & 69.92 & 41.85 & 86.49 & 69.08 & 0.963 & $\begin{array}{l}(0.955, \\
0.971)\end{array}$ \\
\hline
\end{tabular}




\begin{tabular}{|c|c|c|c|c|c|c|c|c|c|}
\hline $\begin{array}{l}\text { Characteri } \\
\text { variables }\end{array}$ & AUC & $\begin{array}{l}\text { Cut-off } \\
\text { values }^{+}\end{array}$ & $\begin{array}{l}\text { Sensitivity } \\
\%\end{array}$ & $\begin{array}{l}\text { Specificity } \\
\%\end{array}$ & PPV \% & NPV $\%$ & $\mathrm{PCC} \%$ & $\begin{array}{l}\text { Odds } \\
\text { ratio }\end{array}$ & $95 \%$ CI \\
\hline \multicolumn{2}{|c|}{$\begin{array}{l}\text { FEF }_{25 \%-75 \%, 763} \\
\% \\
\text { pre- } \\
\text { dicted }\end{array}$} & 84.4 & 70.00 & 68.97 & 42.35 & 87.59 & 69.22 & 0.950 & $\begin{array}{l}(0.940 \\
0.960)\end{array}$ \\
\hline $\begin{array}{l}\text { R5- } \\
\text { R20, } \\
\mathrm{kPa} \cdot \mathrm{L}^{-1} \cdot \mathrm{s}\end{array}$ & 0.604 & 0.88 & 0.65 & 100.00 & 100.00 & 75.40 & 75.44 & 18.961 & $\begin{array}{l}(3.119, \\
115.3)\end{array}$ \\
\hline $\begin{array}{l}\mathrm{X} 5 \\
\mathrm{kPa} \cdot \mathrm{L}^{-1} \cdot \mathrm{s}\end{array}$ & 0.607 & -0.14 & 43.79 & 78.76 & 40.36 & 81.02 & 70.11 & 0.025 & $\begin{array}{l}(0.003, \\
0.223)\end{array}$ \\
\hline $\begin{array}{l}\text { Fres, } \\
\mathrm{L}^{-1} \cdot \mathrm{s}\end{array}$ & 0.634 & 15.71 & 56.95 & 68.32 & 36.91 & 82.98 & 65.53 & 1.081 & $\begin{array}{l}(1.046, \\
1.117)\end{array}$ \\
\hline $\begin{array}{l}\text { FENO, } \\
\text { ppb }\end{array}$ & 0.748 & 41 & 65.29 & 78.16 & 49.33 & 87.37 & 75.00 & 1.024 & $\begin{array}{l}(1.019, \\
1.030)\end{array}$ \\
\hline $\begin{array}{l}\text { EOS in } \\
\text { blood, } \\
\%\end{array}$ & 0.630 & 3.4 & 55.88 & 66.28 & 35.06 & 82.19 & 63.73 & 1.130 & $(1.079,1.182$ \\
\hline $\begin{array}{l}\text { EOS in } \\
\text { blood, } \\
\text { cell } / \mu l\end{array}$ & 0.638 & 360 & 41.76 & 80.65 & 41.28 & 80.96 & 71.10 & 4.367 & $(2.413,7.903$ \\
\hline $\begin{array}{l}\text { Platelets, } \\
\times 10^{\wedge} 9 / \mathrm{L}\end{array}$ & 0.491 & 269 & 80.00 & 24.71 & 25.71 & 79.14 & 38.30 & 0.995 & $(0.995,0.996$ \\
\hline
\end{tabular}

AUC, area under the curve; PPV, positive predictive values; NPV, negative predictive values; PCC: percentages correctly classified; Odds ratio, odds ratio of characteristic variables for predicting BHR; $95 \%$ CI, $95 \%$ confidence interval of odds ratio; $P$ value, the $p$ value of the logistic regression test.

The other abbreviations are as defined for Table 1

${ }^{+}$The cut-off points were selected by maximizing the sum of sensitivity and specificity.

Bold font indicates AUC higher than 0.7.

Table 4. Predictive values of the combination of different variables with FENO in predicting bronchial hyperresponsiveness

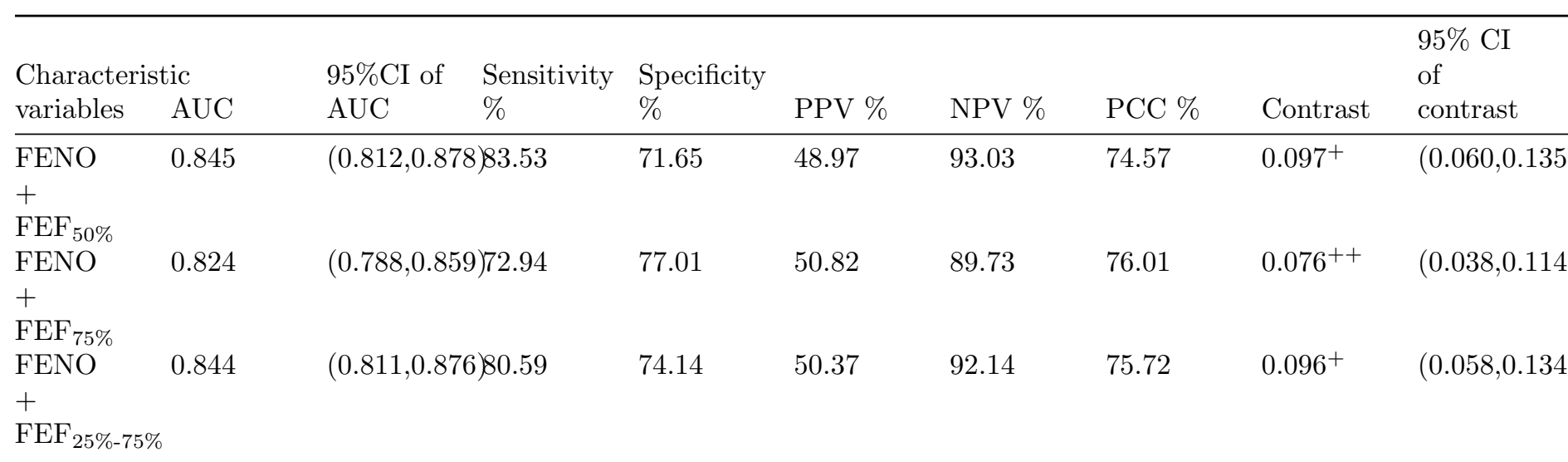




\begin{tabular}{|c|c|c|c|c|c|c|c|c|c|}
\hline $\begin{array}{l}\text { Characterist } \\
\text { variables }\end{array}$ & $\begin{array}{l}\text { tic } \\
\text { AUC }\end{array}$ & $\begin{array}{l}95 \% \mathrm{CI} \text { of } \\
\text { AUC }\end{array}$ & $\begin{array}{l}\text { Sensitivity } \\
\%\end{array}$ & $\begin{array}{l}\text { Specificity } \\
\%\end{array}$ & PPV \% & NPV \% & PCC \% & Contrast & $\begin{array}{l}95 \% \text { CI } \\
\text { of } \\
\text { contrast }\end{array}$ \\
\hline $\begin{array}{l}\mathrm{FENO} \\
+ \\
\mathrm{FEV}_{1} / \mathrm{FVC}\end{array}$ & 0.807 & $(0.769,0.84$ & 4) 85.88 & 61.69 & 42.20 & 93.06 & 67.63 & $0.059^{++}$ & $(0.026,0.092$ \\
\hline
\end{tabular}

95\% CI, 95\% confidence interval; The other abbreviations are as defined for Table 1 and Table 3.

We used the larger of the 2 univariate AUCs to make the comparison;

${ }^{+}$Contrast, the difference between AUC of FENO and AUC of bivariate model;

${ }^{++}$Contrast, the difference between AUC of FEFs and AUC of bivariate model;

$P$ value, contrast's chi-square test for the significance of the contrast.

Table 5. Stratified analysis of patients with chest-tightness: predictive values of combinations of different variables with FENO in predicting bronchial hyperresponsiveness

\begin{tabular}{|c|c|c|c|c|c|c|c|c|c|}
\hline $\begin{array}{l}\text { Characteristi } \\
\text { variables }\end{array}$ & $\begin{array}{l}\text { tic } \\
\text { AUC }\end{array}$ & $\begin{array}{l}95 \% \text { CI of } \\
\text { AUC }\end{array}$ & $\begin{array}{l}\text { Sensitivity } \\
\%\end{array}$ & $\begin{array}{l}\text { Specificity } \\
\%\end{array}$ & PPV \% & NPV \% & $\mathrm{PCC} \%$ & Contrast & $\begin{array}{l}95 \% \text { CI } \\
\text { of } \\
\text { Contrast }\end{array}$ \\
\hline $\begin{array}{l}\text { FENO } \\
+ \\
\mathrm{FEF}_{50 \%} \%\end{array}$ & 0.880 & \multicolumn{2}{|c|}{$(0.806,0.954) 100.00$} & 60.42 & 58.70 & 100.00 & 74.67 & $0.129^{+}$ & $\begin{array}{l}(0.022, \\
0.236)\end{array}$ \\
\hline $\begin{array}{l}\text { FENO } \\
+ \\
\mathrm{FEF}_{75 \%}\end{array}$ & 0.892 & \multicolumn{2}{|c|}{$(0.812,0.972) 70.37$} & 95.83 & 90.48 & 85.19 & 86.67 & $0.080^{++}$ & $\begin{array}{l}(- \\
0.001 \\
0.161)\end{array}$ \\
\hline $\begin{array}{l}\text { FENO } \\
+ \\
\text { FEF }_{25 \%-75 \%}\end{array}$ & 0.884 & \multicolumn{2}{|c|}{$(0.805,0.964) 88.89$} & 75.00 & 66.67 & 92.31 & 80.00 & $0.121^{+}$ & $\begin{array}{l}(0.018 \\
0.224)\end{array}$ \\
\hline $\begin{array}{l}\text { EOS }+^{+} \\
\mathrm{FEF}_{50 \%}\end{array}$ & 0.815 & \multicolumn{2}{|c|}{$(0.716,0.913) 74.07$} & 79.17 & 66.67 & 84.44 & 77.33 & $0.064^{++}$ & $\begin{array}{l}(- \\
0.016, \\
0.144)\end{array}$ \\
\hline $\begin{array}{l}\mathrm{EOS}+ \\
\mathrm{FEF}_{75 \%}\end{array}$ & 0.845 & \multicolumn{2}{|c|}{$(0.750,0.940) 74.07$} & 89.58 & 80.00 & 86.00 & 84.00 & 0.033 & $\begin{array}{l}(- \\
0.017, \\
0.083)\end{array}$ \\
\hline $\begin{array}{l}\mathrm{EOS}+ \\
\mathrm{FEF}_{25 \%-75 \%}\end{array}$ & 0.816 & \multicolumn{2}{|c|}{$(0.715,0.917) 70.37$} & 85.42 & 73.08 & 83.67 & 80.00 & $0.053^{++}$ & $\begin{array}{l}(- \\
0.015, \\
0.120)\end{array}$ \\
\hline
\end{tabular}

The abbreviations are as defined for Table 1, Table 3 and Table 4.

We used the larger of the 2 univariate AUCs to make the comparison;

${ }^{+}$Contrast, the difference between AUC of FENO and AUC of bivariate model;

${ }^{++}$Contrast, the difference between AUC of FEFs and AUC of bivariate model;

$P$ value, significance of the contrast by chi-square test.

Table 6. Predictive value of the combination of different variables with eosinophils in predicting bronchial hyperresponsiveness 


\begin{tabular}{|c|c|c|c|c|c|c|c|c|c|}
\hline $\begin{array}{l}\text { Characterist } \\
\text { variables }\end{array}$ & tic & $\begin{array}{l}95 \% \text { CI } \\
\text { of AUC }\end{array}$ & $\begin{array}{l}\text { Sensitivity } \\
\%\end{array}$ & $\begin{array}{l}\text { Specificity } \\
\%\end{array}$ & PPV \% & NPV \% & $\mathrm{PCC} \%$ & Contrast & $\begin{array}{l}95 \% \text { CI } \\
\text { of } \\
\text { Contrast }\end{array}$ \\
\hline $\begin{array}{l}\mathrm{EOS}+ \\
\mathrm{FEF}_{50 \%}\end{array}$ & 0.786 & \multicolumn{2}{|c|}{$(0.748,0.825) 67.06$} & 76.63 & 48.31 & 87.72 & 74.28 & 0.148 & $(0.097,0.200$ \\
\hline $\begin{array}{l}\text { EOS + } \\
\text { FEF }_{25 \%-75 \%}\end{array}$ & 0.785 & \multicolumn{2}{|c|}{$(0.747,0.823) 67.65$} & 75.29 & 47.13 & 87.72 & 73.41 & 0.147 & $(0.096,0.199$ \\
\hline $\begin{array}{l}\mathrm{EOS}+ \\
\mathrm{FEV}_{1} / \mathrm{FVC}\end{array}$ & 0.734 & \multicolumn{2}{|c|}{$(0.691,0.777) 56.47$} & 80.84 & 48.98 & 85.08 & 74.86 & 0.096 & $(0.045,0.146$ \\
\hline
\end{tabular}

The abbreviations are as defined for Table 1, Table 3 and Table 4.

Contrast, the difference between the AUC of each FEF and the AUC of the bivariate model; we used the larger of the 2 univariate AUCs to make the comparison;

$P$ value, significance of the contrast by chi-square test.

Appendices:

Table 1. AUCs and Error rates in 80/20 split-sample cross validation of prediction models.

\begin{tabular}{|c|c|c|c|c|c|c|}
\hline Characteristic variables & $\begin{array}{l}\text { AUC } \\
\text { Training set1 }\end{array}$ & $\begin{array}{l}\text { AUC } \\
\text { Testing set1 }\end{array}$ & $\begin{array}{l}\text { AUC } \\
\text { Training set2 }\end{array}$ & $\begin{array}{l}\text { AUC } \\
\text { Testing set1 }\end{array}$ & $\begin{array}{l}\text { AUC } \\
\text { Training set3 }\end{array}$ & $\begin{array}{l}\text { AUC } \\
\text { Testing set1 }\end{array}$ \\
\hline $\mathrm{FEV}_{1}, \%$ predicted & 0.661 & 0.599 & 0.683 & 0.547 & 0.648 & 0.656 \\
\hline $\mathrm{FEV}_{1} / \mathrm{FVC}, \%$ & 0.704 & 0.747 & 0.702 & 0.755 & 0.718 & 0.707 \\
\hline $\mathrm{FEV}_{3} / \mathrm{FVC}, \%$ & 0.618 & 0.593 & 0.614 & 0.624 & 0.622 & 0.594 \\
\hline $\mathrm{FEF}_{25 \%}, \%$ predicted & 0.656 & 0.657 & 0.649 & 0.674 & 0.644 & 0.707 \\
\hline $\mathrm{FEF}_{25 \%} / \mathrm{FEV}_{1}, \%$ & 0.579 & 0.620 & 0.559 & 0.666 & 0.575 & 0.628 \\
\hline $\mathrm{FEF}_{50 \%}, \%$ predicted & 0.762 & 0.758 & 0.765 & 0.746 & 0.761 & 0.771 \\
\hline $\mathrm{FEF}_{50 \%} / \mathrm{FEV}_{1}, \%$ & 0.732 & 0.777 & 0.733 & 0.769 & 0.743 & 0.747 \\
\hline $\mathrm{FEF}_{75 \%}, \%$ predicted & 0.727 & 0.826 & 0.763 & 0.690 & 0.750 & 0.736 \\
\hline $\mathrm{FEF}_{75 \%} / \mathrm{FEV}_{1}, \%$ & 0.708 & 0.842 & 0.743 & 0.701 & 0.741 & 0.716 \\
\hline $\mathrm{FEF}_{25 \%-75 \%}, \%$ predicted & 0.759 & 0.780 & 0.769 & 0.743 & 0.765 & 0.764 \\
\hline $\mathrm{FEF}_{25 \%-75 \%} / \mathrm{FEV}_{1}, \%$ & 0.735 & 0.819 & 0.747 & 0.768 & 0.753 & 0.748 \\
\hline $\mathrm{R} 5-\mathrm{R} 20, \mathrm{kPa} \cdot \mathrm{L}^{-1} \cdot \mathrm{s}^{\#}$ & 0.604 & 0.616 & 0.594 & 0.648 & 0.588 & 0.665 \\
\hline $\mathrm{X} 5, \mathrm{kPa} \cdot \mathrm{L}^{-1} \cdot \mathrm{s}^{\#}$ & 0.616 & 0.561 & 0.630 & 0.536 & 0.581 & 0.699 \\
\hline Fres, $\mathrm{L}^{-1} \cdot \mathrm{s}^{\#}$ & 0.640 & 0.608 & 0.635 & 0.639 & 0.616 & 0.697 \\
\hline FENO, ppb & 0.734 & 0.811 & 0.778 & 0.650 & 0.773 & 0.663 \\
\hline Eos in blood, \% \# & 0.646 & 0.603 & 0.666 & 0.543 & 0.648 & 0.603 \\
\hline Eos in blood, cell/ul & 0.639 & 0.588 & 0.665 & 0.513 & 0.640 & 0.592 \\
\hline PLT, *10^9/L & 0.508 & 0.410 & 0.512 & 0.413 & 0.516 & 0.405 \\
\hline
\end{tabular}

AUC, area under the curve; $\mathrm{FEV}_{1}$ : forced expiratory volume in one second; FVC, Forced vital capacity; $\mathrm{FEF}_{25 \%}$, forced expiratory flow (FEF) at $25 \%$ of forced vital capacity; $\mathrm{FEF}_{50 \%}, \mathrm{FEF}$ at $50 \%$ of $\mathrm{FVC} ; \mathrm{FEF}_{75 \%}$, $\mathrm{FEF}$ at $75 \%$ of $\mathrm{FVC}$; $\mathrm{FEF}_{25 \%-75 \%, \mathrm{FEF}}$ at $25 \%$ to $75 \%$ of $\mathrm{FVC}$; R5, total airway resistance at $5 \mathrm{~Hz}$; R20, central airway resistance at $20 \mathrm{~Hz}$; R5-R20, peripheral airway resistance as the difference between 5 and 20 $\mathrm{Hz}$; X5, reactance at $5 \mathrm{~Hz}$; Fres, resonant frequency; FENO, fractional exhaled nitric oxide; Eos: eosinophils; PLT: platelet;

AUC (1st), take the first part as the test set and the rest as the training set, then compute AUC; Average AUC, the average AUC of five different cross-validation model; Whole Model, use all of the data set to 
compute AUC; Error Rate, Error Rate equals to abs (Average AUC - Whole Model AUC) / (Whole Model AUC).

We command that we calculated the four decimal places of AUC, and we kept three decimal places of AUC on the table 4. We use Tabular data which is three decimals to compute Error Rate.

Table 2. Accurate classification rates in $80 / 20$ split-sample cross validation of prediction models.

\begin{tabular}{|c|c|c|c|}
\hline Characteristic variables & $\begin{array}{l}\text { Accurate classification rates } \\
\text { Training set1 }\end{array}$ & $\begin{array}{l}\text { Accurate classification rates } \\
\text { Testing set } 1\end{array}$ & $\begin{array}{l}\text { Accurate classification rates } \\
\text { Training set2 }\end{array}$ \\
\hline $\mathrm{FEV}_{1}, \%$ predicted & 0.590 & 0.783 & 0.709 \\
\hline $\mathrm{FEV}_{1} / \mathrm{FVC}, \%$ & 0.655 & 0.826 & 0.664 \\
\hline $\mathrm{FEV}_{3} / \mathrm{FVC}, \%$ & 0.677 & 0.806 & 0.682 \\
\hline $\mathrm{FEF}_{25 \%}, \%$ predicted & 0.531 & 0.768 & 0.505 \\
\hline $\mathrm{FEF}_{25 \%} / \mathrm{FEV}_{1}, \%$ & 0.540 & 0.790 & 0.522 \\
\hline $\mathrm{FEF}_{50 \%}, \%$ predicted & 0.751 & 0.826 & 0.760 \\
\hline $\mathrm{FEF}_{50 \%} / \mathrm{FEV}_{1}, \%$ & 0.720 & 0.819 & 0.713 \\
\hline $\mathrm{FEF}_{75 \%}, \%$ predicted & 0.690 & 0.826 & 0.706 \\
\hline $\mathrm{FEF}_{75 \%} / \mathrm{FEV}_{1}, \%$ & 0.607 & 0.826 & 0.626 \\
\hline $\mathrm{FEF}_{25 \%-75 \%}, \%$ predicted & 0.691 & 0.819 & 0.690 \\
\hline $\mathrm{FEF}_{25 \%-75 \%} / \mathrm{FEV}_{1}, \%$ & 0.693 & 0.826 & 0.695 \\
\hline R5-R20, $\mathrm{kPa} \cdot \mathrm{L}^{-1} \cdot \mathrm{s}^{\#}$ & 0.599 & 0.777 & 0.607 \\
\hline $\mathrm{X} 5, \mathrm{kPa} \cdot \mathrm{L}^{-1} \cdot \mathrm{s}^{\#}$ & 0.704 & 0.777 & 0.652 \\
\hline Fres, $\mathrm{L}^{-1} \cdot \mathrm{s}^{\#}$ & 0.673 & 0.791 & 0.668 \\
\hline FENO, ppb & 0.733 & 0.819 & 0.769 \\
\hline Eos in blood, \% \# & 0.663 & 0.783 & 0.679 \\
\hline Eos in blood, cell/ul & 0.643 & 0.761 & 0.661 \\
\hline PLT, *10^9/L & 0.401 & 0.790 & 0.394 \\
\hline
\end{tabular}

The abbreviations are as defined for Table 1

Figure 1. ROC curves for the models of FEF combined with FENO for predicting positive bronchial provocation tests $(n=692)$.

(A) $\mathrm{FEF}_{50 \%}$ combined with FENO. $\mathrm{AUC}_{\text {Model }}=0.845$ (95\% CI, 0.812-0.878); $\mathrm{AUC}_{\mathrm{FENO}}=0.748(95 \%$ CI, 0.702-0.793; $P<0.001$, compared with the model); $\mathrm{AUC}_{\mathrm{FEF} 50 \%}=0.762(95 \% \mathrm{CI}, 0.721-0.803 ; P<.001$, compared with the model).

(B) $\mathrm{FEF}_{75 \%}$ combined with FENO. $\mathrm{AUC}_{\text {Model }}=0.824$ (95\% CI, 0.788-0.859); $\mathrm{AUC}_{\mathrm{FENO}}=0.748(95 \% \mathrm{CI}$, 0.702-0.793; $P<0.001$, compared with the model); $\mathrm{AUC}_{\mathrm{FEF} 75 \%}=0.745$ (95\% CI, $0.703-0.786 ; P<0.001$, compared with the model).

(C) $\mathrm{FEF}_{25 \%-75 \%}$ combined with FENO. $\mathrm{AUC}_{\text {Model }}=0.844$ (95\% CI, 0.811- 0.876); $\mathrm{AUC}_{\mathrm{FENO}}=0.748(95 \%$ CI, 0.702-0.793; $P<0.001$, compared with the model); $\mathrm{AUC}_{\mathrm{FEF} 25 \%-75 \%}=0.763$ (95\% CI, $0.723-0.802 ; P<$ 0.001, compared with the model).

(D) $\mathrm{FEV}_{1} / \mathrm{FVC}$ combined with FENO. $\mathrm{AUC}_{\text {Model }}=0.807$ (95\% CI, 0.769-0.844); $\mathrm{AUC}_{\mathrm{FENO}}=0.748(95 \%$ CI, 0.702-0.793; $P=0.001$, compared with the model); $\mathrm{AUC}_{\mathrm{FEV} 1 / \mathrm{FVC}}=0.713$ (95\% CI, 0.669-0.758). 


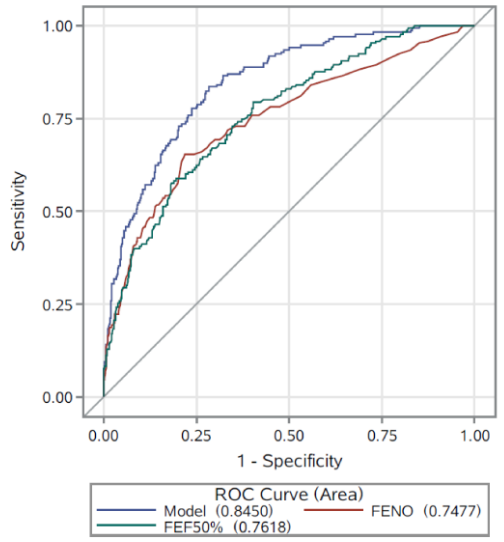

(A)

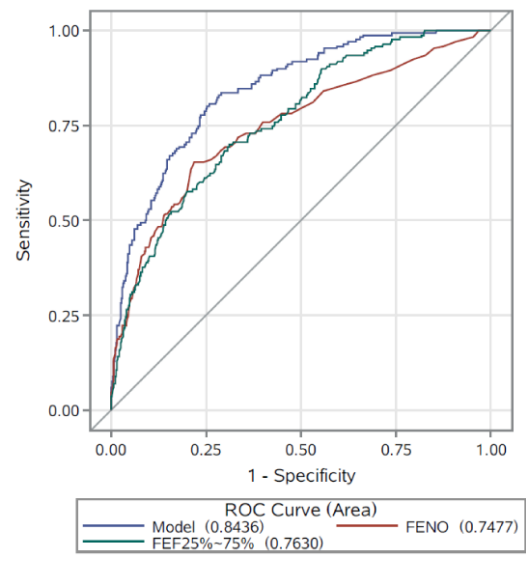

(C)

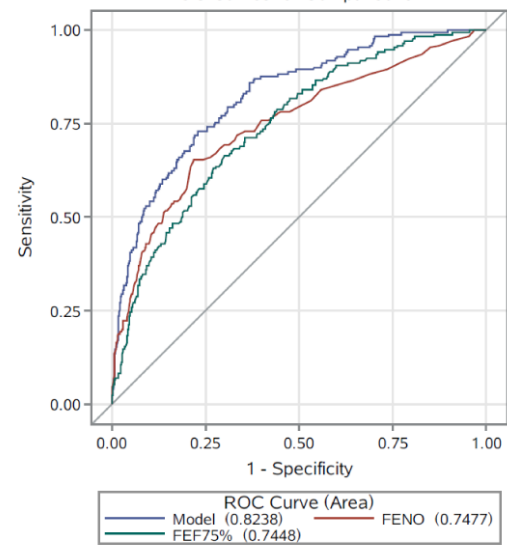

(B)

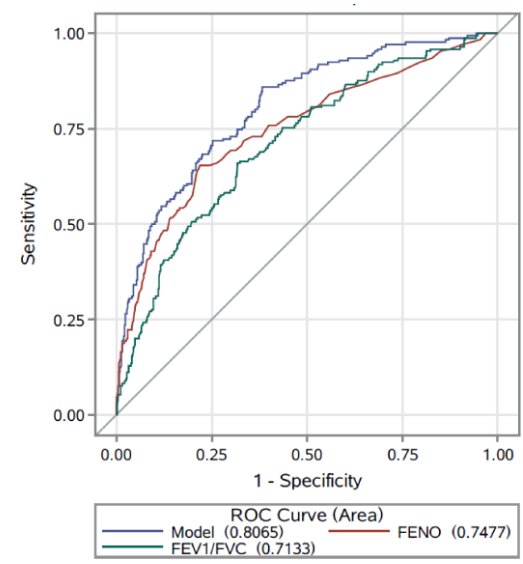

(D)

AUC: area under the curve; ROC: receiver operating characteristic; FENO: fractional exhaled nitric oxide; $\mathrm{FEV}_{1}$ : forced expiratory volume in 1 second; FVC: forced vital capacity; FEF: forced expiratory flow; $\mathrm{FEF}_{50 \%}$ : FEF at $50 \%$ of FVC; $\mathrm{FEF}_{70 \%}$ : FEF at $70 \%$ of $\mathrm{FVC} ; \mathrm{FEF}_{25 \%-75 \%}$ : FEF at $25 \%$ to $75 \%$ of $\mathrm{FVC}$.

Figure 2. ROC curves of dichotomous state variables of the models of FEFs combined with FENO in predicting positive bronchial provocation tests $(n=692)$.

(A) $\mathrm{FEF}_{50 \%}$ combined with FENO. $\mathrm{AUC}_{\text {Model }}=0.809$ (95\%CI, 0.786-0.878);

(B) $\mathrm{FEF}_{75 \%}$ combined with FENO. $\mathrm{AUC}_{\text {Model }}=0.797$ (95\%CI, 0.768-0.866);

(C) $\mathrm{FEF}_{25 \%-75 \%}$ combined with FENO. $\mathrm{AUC}_{\text {Model }}=0.802(95 \% \mathrm{CI}, 0.780-0.874)$.

The abbreviations are as defined for Figure 1. 


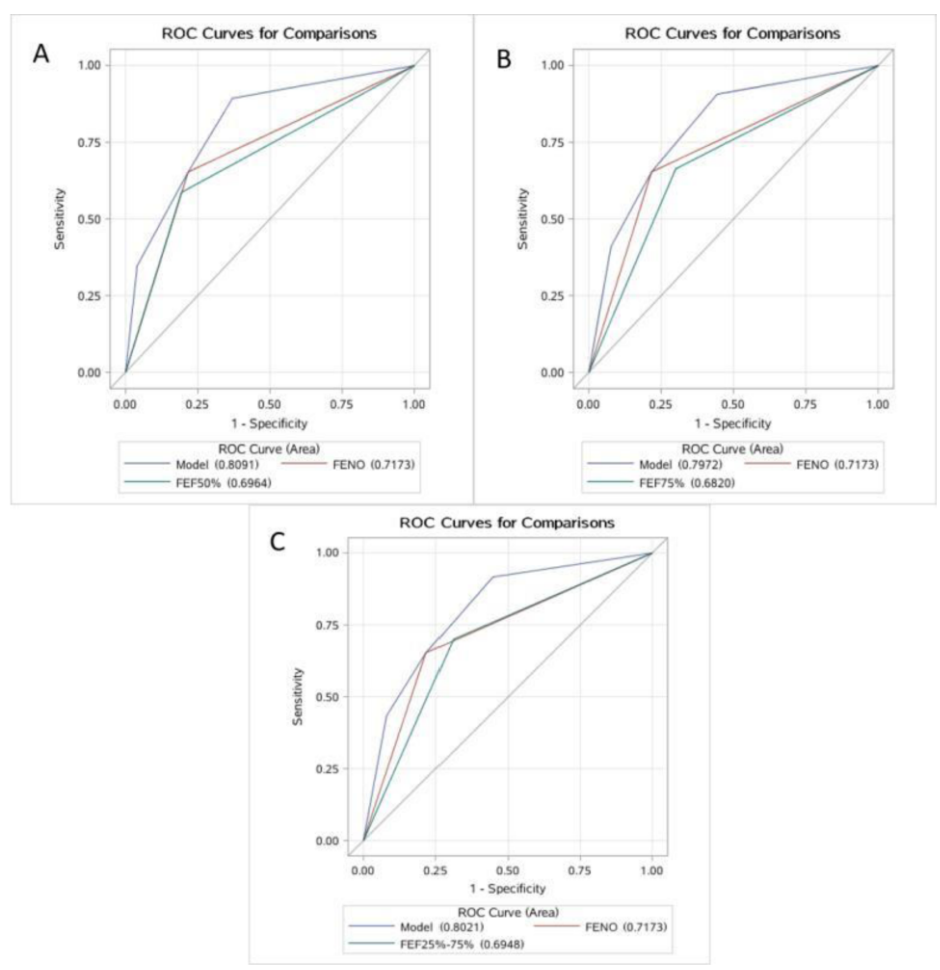

